Edição Especial: Produção de Conhecimento Científico em Marketing

\title{
Perspectivas, avanços e resistências na produção de conhecimento em Marketing
}

\section{Prospects, achievements and resistance in the knowledge production in Marketing}

\section{Eduardo André Teixeira Ayrosa}

Universidade Unigranrio

PPGA - Programa de Pós-Graduação em Administração

e-mail: eayrosa@gmail.com

Recebido em 18 de março de 2013. Aprovado em 24 de março de 2013

Editor Responsável: Edson Roberto Scharf, Dr.

Autor convidado para edição especial

\section{Resumo}

Este artigo pretende refletir sobre as perspectivas da produção em marketing no Brasil a partir da dualidade historicamente estabelecida entre pesquisadores praticantes da investigação quantitativa e qualitativa. Trata-se, portanto, de um ensaio inspirado pelos textos de Salomão Farias sobre a pesquisa quantitativa e de Francisco David Giovanni Vieira sobre a pesquisa qualitativa em marketing no Brasil. Assumindo que a discussão sobre o embate qualitativos-quantitativos é de caráter político, procuro contextualizar esses dois lados da questão em termos de visão de mundo, movimentando a discussão para a polaridade positivismo-relativismo. Concluo discutindo a educação dos doutores e mestres brasileiros, e clamando pela formação de pesquisadores com visões de mundo mais divergentes.

Palavras-chave: marketing, epistemologia, metodologia

\begin{abstract}
This paper aims to reflect about the perspectives of academic production in marketing in Brasil departing from a historically established clash between researchers dedicated to quantitative and qualitative approaches to investigation. It is an essay inspired by the works by Salomão Frias on quantitative research, and Francisco David Giovanni Vieira on qualitative research on marketing in Brazil. Assuming that this qualitativequantitative clash is of political character, I seek to contextualize both sides of this discussion according to their worldviews, moving the axis of discussion to a positivistic-relativistic duality. I conclude disserting about the education of Brazilian academics, and claiming for the formation of researchers with more divergent worldviews.
\end{abstract}

Keywords: marketing, epistemology, methodology 
Os artigos de Vieira e Farias traçam um sólido panorama sobre as formas qualitativas e quantitativas de produção de conhecimento em marketing e consumo no Brasil. Perspectivas, avanços e resistências nessa produção estão irremediavelmente atrelados a esse embate. Meu objetivo aqui é refletir sobre este conflito, seus fundamentos, e as formas de superá-lo. Acredito que dessa forma ajudamos a abrir caminhos importantes para a produção em marketing no Brasil.

Gostaria de iniciar este ensaio refletindo sobre a natureza do tema. O que está aqui sobre a mesa é uma discussão sobre uma relação de alteridade, um embate epistemo-metodológico estabelecido ao longo do tempo em bases politicamente sólidas, mas logicamente nem tanto. Afinal, se a todos os pesquisadores em administração neste mundo tivesse sido oferecida a oportunidade de pensar, ao longo de seus anos de formação, na natureza dos problemas de pesquisa que podem vir a investigar e nas diversas formas de abordá-los, todos usaríamos os métodos mais adequados a cada classe de problema. Em minhas aulas de metodologia de pesquisa sempre fiz questão de afirmar que os métodos são consequência de nossas visadas onto-epistemológicas, visada esta que define nossa compreensão do objeto de pesquisa. Quanto mais divergente é nossa forma de ver o mundo, mais diversa é nossa capacidade de abordar o objeto (MITTROFF, 1972). Uma mente divergente é capaz de abordar problemas de pesquisa com um olhar irremediavelmente multifacetado, é capaz de ver o problema de pesquisa como uma sucessão de planos distintos, cada um mostrando uma história possível, um conjunto possível de achados, seus olhos veem problemas mais ou menos como os de Picasso, em sua fase cubista, viam uma natureza morta. A mente divergente escolheria um plano, o exploraria, passaria para outros planos, numa sucessão de estudos que comporiam projetos multimetodológicos. Mas raramente produzimos mentes divergentes. Neste embate epistemológico em que nos encontramos, onde faz sentido pensar numa conciliação entre métodos qualitativos e quantitativos, parece que temos formado mentes que se sentem mais confortáveis com a convergência do que a divergência. Temos formado doutores não em organizações, marketing ou finanças, mas sim doutores em experimentos, modelagem estrutural, antropologia organizacional, ou teoria fundamentada. A nossa discussão parece ser mais de natureza política do que ontológica ou epistemológica, muito menos metodológica. Assim sendo, meu objetivo neste ensaio é explorar as diferenças entre estes dois "mundos" e procurar oferecer elementos que nos permitam ver estes conflitos políticos de forma promissora sim, porque este conflito traz em seu bojo a semente de sua solução.

Todo pesquisador lança - ou deveria lançar - seus olhos ao mundo com clara intenção de conhecer algo. Este olhar é não apenas prenhe de vontade em relação ao objeto que vê. Este olhar, assim como a vontade que dele emana, são largamente determinados pela forma como o observador compreende a natureza daquilo que vê. Esta compreensão vai definir a posição do objeto em relação ao seu observador de tal forma que abrirá possibilidades de indagação. Hessen (1999), que vê o conhecimento como uma relação entre um sujeito (aquele que conhece, um sujeitocognoscente) e um objeto (o que é conhecido, ou se dá a conhecer, ou o sujeito cognoscível), estabelece posições extremas em relação à possibilidade e à natureza do conhecimento. Em um lado prevalece o objeto, ou seja, o sujeito cognoscente é determinado pelo objeto. $\mathrm{Na}$ outra extremidade esta relação aparece invertida, ou seja, o objeto é determinado pelo sujeito. No primeiro caso, a fonte do conhecimento é a experiência, no segundo, a razão. Em 
termos epistemológicos, de um lado temos o empirismo, e do outro, o racionalismo. Tais posições são evidentemente eivadas pela dúvida sobre a efetiva possibilidade de determinação de um pelo outro, o que em termos gerais significa fazer uma crítica à própria possibilidade de conhecimento nestes termos. Ao não subscrever às extremidades deste continuum epistemológico, tanto praticantes da pesquisa quantitativa quanto qualitativa são, para usar as palavras de Hessen (1999), céticos. Praticantes da pesquisa quantitativa priorizam cuidados relativos à confiabilidade e validade de sua investigação devido à constante incerteza a respeito da teoria que fundamenta suas expectativas empíricas e dos números que decorrem do esforço de coleta de dados. Praticantes da pesquisa qualitativa, por sua vez, rejeitam a priori a possibilidade de reflexão ou observação puras produzirem conhecimento válido, visto que essa é uma representação de um fato realizada por um sujeito, ou seja, uma negociação entre um sujeito cognoscente e um cognoscível. Não há acesso direto ao conhecimento, todos rejeitam dogmas. Retornando à classificação proposta por Hessen (1999), talvez sejamos todos "intelectualistas": tanto razão quanto experiência participam da formação do conhecimento. As opções metodológicas afastam praticantes da pesquisa qualitativa e quantitativa, não necessariamente implicam em diferenças epistemológicas tão profundas. Mas tais diferenças existem, e não são só de ordem política.

Para discutir isso, primeiramente gostaria de perguntar se "quantitativismo" e "qualitativismo" seriam exatamente os problemas em nossa mesa de trabalho. É inapropriado reduzir uma discussão tão importante à presença versus ausência de números. Os artigos de Farias e Vieira deixam isso bastante claro. Para os pesquisadores quantitativos, a quem Farias associa a figura do cadeado fechado, a boa pesquisa é aquela em que o sujeito aparece afastado do objeto, num processo em que teorização e empiria ocupam tempo e espaço diferentes. $\mathrm{O}$ acesso do pesquisador aos informantes é feito com todos os cuidados para que não ocorram "contaminações" entre as partes. Rigor na coleta e análise de dados, certificação numérica de validade, aplicação de técnicas estatísticas, todos contribuem para uma maior objetividade do pesquisador. A objetividade, tão importante neste jogo, é determinada pela tentativa de blindar o trabalho da influência de variáveis que não tenham sido anteriormente levadas em conta na elaboração da fundamentação teórica e proposição de hipóteses - o "racional" do trabalho. O objeto surge como códigos ou medidas, não há espaço para o surgimento se sua subjetividade. Tal descrição nos permite reconhecer os praticantes de pesquisa quantitativa como adeptos do positivismo, onde fatos sociais devem ser explicados por outros fatos sociais, mas não pela consciência dos atores sociais (DURKHEIM, 1982). Tal postura positiva remete ao realismo crítico (HUNT, 1990), postura que, oposta a formas de relativismo, acredita na existência de uma realidade objetiva e independente de seus observadores. Se existe o "real", existem formas precisas e verossímeis de representá-lo, mesmo que este "mundo real" não possa ser efetivamente apreendido por razão ou sentidos. O uso de números é um efeito da postura ontológica e epistemológica do pesquisador.

Quanto à prática da pesquisa qualitativa, o informante é, de fato, um sujeito cognoscível, uma vez que aqui sua subjetividade tem valor. Note que, neste caso, o objeto enquanto sujeito cognoscível é humano e tem intenção, tem vontade, pensa e se comporta de forma mais ou menos coerente com a sua razão. O conhecimento objetivo do fato "real" que constitui o foco principal do positivismo hipotético-dedutivo é aqui colocado em questão. Posições onto- 
epistêmicas aproximam-se do relativismo (ANDERSON 1986, 1988), rejeitam o acesso à realidade (HIRSCHMANN, 1986), acreditando que ela é negociada entre observadores e observados (HIRSCHMAN; HOLBROOK, 1992). A metáfora do "cadeado aberto" atribuída à pesquisa qualitativa por Farias vê nesta abertura, em relação ao fechamento da pesquisa quantitativa, uma faca de dois gumes. A abertura a insights valiosos que seriam de difícil realização por praticantes da pesquisa quantitativa vem a custo da fragilidade das conclusões, fruto da subjetividade do pesquisador. Mas, como vimos em notas sobre a pesquisa quantitativa feita anteriormente, a subjetividade que mais interessa aqui, a subjetividade à qual a pesquisa qualitativa efetiva e completamente se abre, é a subjetividade do informante, do sujeito cognoscível. Como o praticante da pesquisa qualitativa quer ter acesso a uma subjetividade e sabe que a realidade se faz no encontro - dialético - entre as subjetividades do observador e do observado (como o encontro do senhor e do escravo em Hegel (1999), a subjetividade do observador é uma consequência lógica do processo). Tal encontro de subjetividades afronta diretamente a crença ontológica na objetividade do real partilhada por pesquisadores positivistas.

A dominância paradigmática do positivismo, expressa em número de trabalhos publicados (SAMPAIO et al, 2012), torna o encontro de subjetividades um problema político de difícil solução para praticantes da pesquisa qualitativa, frequentemente de orientação mais próxima ao relativismo. $\mathrm{O}$ texto de Vieira é claro neste aspecto. Ele inicia dissertando sobre a posição política da pesquisa qualitativa em relação ao mainstream da área, num movimento típico de um pesquisador para quem o objeto de observação não se separa de seu contexto (tal menção a questões políticas não surge no texto de Farias simplesmente porque ela não cabe em seu foco de análise). Voltando ao texto de Vieira, após a introdução ele segue em uma clara explanação sobre a prática da pesquisa qualitativa, mas não sem dar atenção a validade, um conceito fundamental em pesquisa quantitativa, mas de caráter relativamente mal definido na pesquisa qualitativa. Afinal, se a pesquisa qualitativa está relacionada ao relativismo, e este recusa não apenas o acesso, mas a simples existência de uma realidade objetiva, qual viria a ser então um critério de validade em pesquisa qualitativa? Para Kvale (1995) o conceito de validade é uma realidade socialmente construída, e atende a um conjunto de interesses políticos. Um bom caminho para resolver este problema talvez resida na responsabilidade do pesquisador para com o relato que produz (KORO-LJUNGBERG, 2011): "Responsabilidade...pede aos pesquisadores para bem receber o Outro, para permanecer continuamente sensíveis aos dados e interações inesperadas com participantes e comunidades", (p. 605).

Até este ponto tenho trabalhado a pesquisa quantitativa como afinada com o positivismo hipotético-dedutivo, e a qualitativa como próxima do relativismo. Mas nem sempre estas relações acontecem. Não é razoável assumir que todos os corpos de dados produzidos para investigação qualitativa serão analisados de forma a um pesquisador positivista classificar tal análise como demasiadamente subjetiva. Por exemplo, um trabalho com um conjunto de categorias analíticas definidas a priori e relatado de forma a afastar a subjetividade do pesquisador (o que inclui usar a terceira pessoa ou o "nós majestático") pode atender às expectativas de uma audiência positivista. $\mathrm{O}$ reconhecimento do objeto de pesquisa como uma realidade objetiva

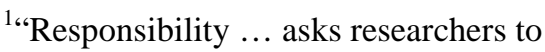
welcome the Other, to continuously stay sensitized to data and unexpected interactions with participants and communities." participants and communities." to data and unexpected interactions with participants and communities."
} 
clara e independente dos valores dos sujeitos envolvidos é fundamental neste momento. Tal reconhecimento pode ser evidenciado no cuidado em atender a critérios de validade do trabalho qualitativo como aqueles descritos em Kirk (1986), Lincoln \& Guba (1985), ou Koro-Ljungberg (2011). Estes procedimentos podem ser adotados como via de regra por praticantes da pesquisa qualitativa, uma vez que ajudam a construir pontes entre os paradigmas.

De forma análoga, o simples uso de números não nos permite classificar um trabalho como essencialmente positivo ou de caráter puramente realista. Dados numéricos provenientes de estatísticas populacionais, por exemplo, podem inspirar a reflexão sobre problemas que podem ser alvo de investigação interpretativa. Por outro lado, relatos como os de Huff (1954) ou Gould (1996) expõem a possibilidade de análise estatística de dados qualitativos ser usada, mesmo intencionalmente, para dizer coisas que "não estão lá". A responsabilidade, a que se refere Koro-Ljungberg (2011) no âmbito da investigação qualitativa, deve também ser alvo de atenção entre praticantes da pesquisa quantitativa.

Se os conflitos paradigmáticos entre pesquisadores parecem ser mais facilmente explicados por desacordos quanto a visões positivista e relativista de mundo, talvez os termos "quantitativo" e "qualitativo" sejam usados nas conversas entre acadêmicos, nos congressos, e na avaliação de trabalhos, de forma a ocultar estas diferenças: o fetiche dos números. A forma mais eficaz para desvelar um fetiche é por todos sabida: informação esclarecedora.

Aqui chegamos à educação do pesquisador. Tanto Vieira quanto Farias referem-se ao processo de formação do pesquisador brasileiro em marketing como fortemente orientado para o positivismo e à visão da pesquisa em ciências naturais como um modelo a ser seguido. Como de um lado os programas de pós graduação motivam fortemente seus doutorandos e mestrandos a produzirem intensamente com seus orientadores, e de outro $\mathrm{o}$ mercado de trabalho acadêmico procura por candidatos cada vez mais produtivos, os programas tenderão a priorizar formas de produção científica seguras e eficazes. Admitamos, é mais rápido produzir um pesquisador produtivo num paradigma positivista que relativista. Os caminhos da estatística são mais claros que os da análise de conteúdo/discurso/narrativa. Os números mediam objetivamente as relações entre pesquisadores e o fato social que querem conhecer, não são $O$ fato social. Assim sendo, a estatística, em sua indeterminação fundadora, opera com probabilidades de ocorrência de eventos com os quais ela mesma nada tem a ver, ela apenas conta e indica. No entanto, é uma caixa que poucos pesquisadores em marketing - e em muitas outras áreas de conhecimento - efetivamente conseguem abrir. Programas como o SAS ou SPSS nos mantêm relativamente afastados de seus fundamentos. Para usar um exemplo simples: quantos de nossos doutorandos, usando as informações que recebem nos cursos de estatística que fazem, conseguem elaborar matematicamente sobre as diferenças entre rotação oblíqua e varimax? Sabemos qual variedade usar dependendo da situação de análise, mas não abrimos a caixa. Esse cadeado é difícil de abrir porque a chave - a matemática está frequentemente esquecida no passado. Os pesquisadores dedicados à interpretação também dependem de saberes filosofia, sociologia, hermenêutica, semiologia - que raramente integram o núcleo disciplinar dos doutorados em administração e, quando existem, estão esquecidos no passado. Os interpretativistas não têm "SPSS" porque seus dados - majoritariamente textos, mas também imagens e filmes - se confundem não apenas com o fato social observado, mas também com o juízo do pesquisador 
(ARNOLD \& FISCHER, 1994). O treinamento deste pesquisador no doutorado é muito menos estruturado que o do positivista. Poucos cursos têm em seu núcleo disciplinar alguma matéria dedicada exclusivamente à interpretação de textos e imagens. A sistematização do trabalho de análise é também nebulosa. Enquanto programas como SAS ou SPSS mais do que ajudam quem usa números porque na sua ausência o trabalho seria hercúleo, quem interpreta textos frequentemente aprende como sistematizar a sua análise enquanto a faz. É mais ou menos como ler o manual do avião enquanto se está pilotando. $\mathrm{O}$ uso de programas como NVIVO ou Atlas.ti ainda não é ponto pacífico entre os pesquisadores, ainda mais porque estes programas fazem pouco pelos dados além de sistematizá-los. Seu uso, no entanto, alavanca o processo de análise e é um forte aliado no treinamento de pesquisadores porque tangibiliza 0 processo de análise.

Enfim, se procuramos por alguma forma de avançar na produção de conhecimento em marketing no Brasil, devemos nos dedicar a pensar de forma mais ampla e responsável sobre a formação acadêmica de nossos doutorandos. Se os valores que dirigem este pensamento são instrumentais, corremos o risco de ganhar em volume mas perder em relevância, o que é problemático num momento em que o impacto da produção acadêmica está se tornando um indicador mais forte que o volume de artigos publicados. A diversidade de problemas relacionados a marketing com que nos deparamos no Brasil é imensa. Temos uma vasta classe média sobre a qual ainda conhecemos pouco. O modo de representação desta população de consumidores pede por formas novas de conhecimento, formas que pouco provavelmente poderão ser importadas dos EUA. Como mencionei na introdução, Mittroff (1979) usa a figura das mentes convergentes e divergentes proposta por Hudson (1966) para discutir o mito da objetividade. Mentes convergentes tendem a procurar por problemas bem definidos para os quais há uma resposta clara. Mentes divergentes, por sua vez, tendem a preferir problemas nebulosos e que podem ser abordados de maneiras diversas. Ao priorizar a educação quantitativa de nossos doutores, estamos priorizando a produção de mentes convergentes. Enquanto ganhamos em volume de publicações, talvez isso venha em detrimento da capacidade de nossos pesquisadores olharem para os consumidores e mercados com os olhos criativos $\mathrm{e}$ inquisidores das mentes divergentes. $\mathrm{O}$ processo de preparação da tese necessariamente passa por um estágio divergente - o de concepção - e um convergente - o de definição final do foco de análise. Acredito que nossas perspectivas futuras na área de marketing e estudos de consumo serão tão mais ricas quanto a nossa capacidade de fomentar as duas formas de pensar - divergente e convergente - em nossos programas de pós-graduação. É nossa responsabilidade como intelectuais fomentar o desenvolvimento de mentes que saibam fazer perguntas incômodas, que saibam desafiar teorias produzidas em países exportadores de conhecimento.

No início deste artigo me referi ao olhar do pesquisador (o sujeito) sobre o objeto de pesquisa como um olhar "prenhe de vontade". É difícil não reconhecer no observador um olhar cuja intenção de apreender o objeto não já o defina em parte. Como pesquisador, meu olhar é forjado em meus anos de formação científica e de vida profissional. Se minha formação priorizou uma forma de ver o mundo, é muito provável que esta seja a forma não apenas como eu verei problemas de pesquisa que dali em diante se coloquem, mas também é provável que eu treine pesquisadores da mesma forma, usando a mesma visão de mundo. Se procurarmos por uma educação mais divergente do pesquisador, precisaremos 
de mais diversidade nos corpos docentes nos programas de pós-graduação.

Há como conciliar essas visões de mundo? Desde que Kuhn (1982) trouxe o conceito de incomensurabilidade para nossas vidas, parece ser inútil usar princípios de um paradigma para criticar conclusões produzidas por outro. No entanto, a consciência do valor de visadas paradigmaticamente distintas, atingível pelo treinamento de doutores capazes de pensar conceitualmente e bem formados em filosofia da ciência e formas distintas de análise, pode aproximar tais visadas fazendo-as por vezes complementares. As perspectivas de produção relevante em marketing no Brasil serão tão mais brilhantes quanto a nossa capacidade de treinar doutores de forma diversa, formar doutores preparados para olhar para realidades diversas que clamam por soluções metodológicas baseadas em visões de mundo por vezes incomensuráveis. Se o que fundamenta o desacordo é uma luta política, a conciliação passa irremediavelmente por compreensão racional, entendimento desprendido, e consciência crítica sobre nosso papel na sociedade.

\section{Referências:}

ANDERSON, P. F. On method in consumer research: A critical relativist perspective. Journal of Consumer Research, v.13, p.155-173, 1986.

ANDERSON, P. F. Relativism revidivus: In defense of critical relativism. Journal of Consumer Research, v.15, n.3, p.403406, 1988.

ARNOLD, S. J.; FISCHER, E. Hermeneutics and Consumer Research. Journal of Consumer Research, v.21, p.55-70, 1994.

DONALDSON, L. Organization Theory as a Positive Science. In $\mathrm{H}$. Tsoukas; C. Knudsen (Eds.), Oxford Handbook Of
Organization Theory (p. 39-62). Oxford: Oxford University Press, 2005.

DURKHEIM, E. The rules of sociological method. New York: Free Press, 1982.

HEGEL, G. W. F. Fenomenologia do espírito - parte 1. Petrópolis: Vozes, 1999.

HESSEN, J.; CUTER, J. V. G. Teoria do Conhecimento. São Paulo: Martins Fontes, 1999.

HIRSCHMAN, E. C. Humanistic inquiry in Marketing research: Philosophy, method, and criteria. Journal of Marketing Research, v.32, p.237-249, 1986.

HIRSCHMAN, E. C.; HOLBROOK, M. $B$. Postmodern consumer research: the study of consumption as text. Oxford: Sage Publications, 1992.

HUFF, D.; GEIS, I. How to Lie with Statistics. New York: W. W. Norton, 1954.

HUNT, S. D. Truth in Marketing Theory and research. Journal of Marketing, v.54, p.1-15, 1990.

GOULD, S. J. The Mismeasure of Man. Oxford: Norton, 1996.

HUDSON, L. Contrary imaginations: Psychological study of the English schoolboy. New York: Penguin Books, 1968.

KIRK, J.; MILLER, M. L. Reliability and validity in qualitative research, v.1. London: Sage, 1986.

KUHN, T. S. Commensurability, comparability, communicability. Proceedings of the Biennial Meeting of the Philosophy of Science Association, p. 669-688, 1982.

KORO-LJUNGBERG, M. Validity, Responsability, and Aporia. Qualitive Inquiry, v.16, n.8, p.603-610, 2011. 
LINCOLN, Y. S.; GUBA, E. G. Naturalistic Inquiry. New York: Sage Publications, 1985.

MITROFF, I. I. The mith of objectivity or why science needs a new psychology of science. B-613-B618, 1972.

SAMPAIO, C. H.; PERIN, M. G.; LUCE, F. B.; SANTOS, M. J.; SANTINI, F. O.; OLIVEIRA, M. O. R.; Pesquisa científica da área de Marketing no Brasil: Uma revisão da primeira década do século 21 . Revista de Administração Contemporânea, v.16, n.3, p.459-478, 2012. 